\title{
Photoperiodism and pen colouration: effects on the performance characteristics of
} growing gilts

\author{
${ }^{1}$ Adebiyi, O. A. and ${ }^{2}$ Adelowo, O. V. \\ ${ }^{\prime}$ Department of Animal Science, University of Ibadan, Ibadan, Nigeria \\ ${ }^{2}$ Federal College of Animal Health and Production Technology, \\ Vom, Jos, Nigeria
}

Abstract Corresponding author: femibiyi01@gmail.com

This study was carried out to investigate the effects of photoperiod and pen colouration on growth performance characteristics of grower gilts. Forty-eight crossbred (Large white $x$ Landrace) grower gilts at 16 weeks of age with mean body weight of $16.82 \pm 0.26 \mathrm{~kg}$ were randomly allotted to four (4) treatments. Pens were painted with different colours: pantone441 (control), pantone293 (blue), pantone185 (red) and pantone361 (green) and exposed to photoperiods of 12,15 and 18 hours (h). The experimental design was $4 \times 3$ factorial arrangement in a completely randomised design. Performance parameters measured were Feed Intake (FI), Final Weight (FW) and Weight Gain (WG), while Feed Conversion Ratio (FCR) was calculated weekly throughout the 8 weeks of the experiment. Respiratory and rectal temperatures were monitored. The ambient temperature-humidity index (THI) was also monitored. The main effect of pen colour showed significant $(p<0.05)$ variations in $F W$ and $W G$ of gilts with values ranging from $33.68 \pm 0.78 \mathrm{~kg}$ (red) to $31.00 \pm 2.13$ $\mathrm{kg}$ (green) and $2.10 \pm 0.10 \mathrm{~kg}$ (red) to $1.77 \pm 0.25 \mathrm{~kg}$ (green) respectively. Significant reduction was observed in the FCR of gilts in red pens (4.02 \pm 0.30$)$ compared to their counterparts in

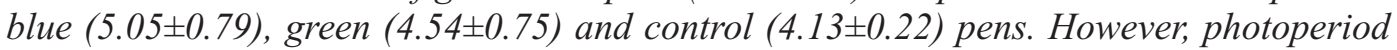
had no significant effects on $F W$ and $W G$ across the treatments. Gilts in $12 \mathrm{~h}$ photoperiod had the highest significant $(p<0.05)$ FI and FCR of $9.21 \pm 1.68 \mathrm{~kg}$ and $4.84 \pm 0.83$ compared to $7.97 \pm 0.19 \mathrm{~kg}$ and $4.22 \pm 0.52$ recorded for gilts exposed to $18 \mathrm{~h}$ photoperiod respectively. Interactions of pen colour $x$ photoperiods: control pen $x 12 \mathrm{~h}(32.18 \pm 0.57)$, blue pen $x 12 \mathrm{~h}$

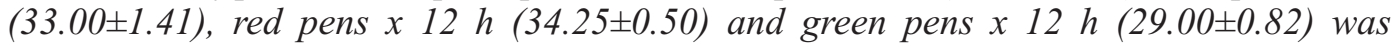
significant for FW. The same trend was also observed for WG, FI and FCR. The THI varied from 79.5 to 71.5 throughout the period of the experiment. It can therefore be concluded that increasing the photoperiod (hour of day-length) beyond 12 hours may not lead to additional positive impact on the weight changes of gilts but resulted in better feed conversion ratio. However, gilts housed in red pen had better feed utilisation.

Keywords: Photoperiod, pen colour, performance, grower gilts

\section{Introduction}

Pig performance and welfare are influenced by non-physical conditions of their environment. Pens are generally constructed without considering the welfare and behaviour of these animals and this could lead to poor performance. There is therefore a need to improve the comfort, welfare and environmental condition of these animals to enhance their production and optimal performance. One of the ways this can be achieved is by adding aesthetics beauty to the pen to help boost their performance (Adelowo and Adebiyi, 2016). There were reports of notable receptability and increased performance due to colour and photoperiod in swine from temperate environment. However, these observations are yet to be documented for swine in hot humid environment. The effect of pen colour with the influence of photoperiod on production has not been explored in the 


\section{Photoperiodism and pen colouration}

tropics and Nigeria in particular. Pigs like any other mammal are very intelligent, and have a good understanding of their surroundings (Taylor, 2006) and have dichromatic vision i.e. only two pigment cones that create colour (Neitz and Jacobs, 1989). The retina of pigs contains a substantial population of two types of cones with sensitivity peaks at about $439 \mathrm{~mm}$ (indigo) and $556 \mathrm{~mm}$ (green-yellow) in the spectrum of visible light (Neitz and Jacobs, 1989). Pigs generally prefer lighted areas as opposed to darkness (Taylor et al., 2006). For example, Tanida et al. (1996) found that piglets tend to move toward more brightly illuminated areas and they use vision for a wide range of tasks from foraging to communication, discriminating between individuals, and social learning. According to Adelowo and Adebiyi (2016), weaner pigs are sensitive to colours especially red, green and blue. Environmental factors are imperative in the production of any livestock due to their direct influence on the physiological processes of the animal (Rivera et al., 2005). In pig production, light has been found to affect the feed intake, improve milk let down and encouraged suckling in piglets (Taylor, 2006). Temperature and light are also viewed as major environmental factors affecting animal physiology (Rivera et al., 2005) with temperature being considered the most important factor. Taylor (2010) investigated the effects of "night lighting" in piggeries and reported that it is sometime necessary. However, studies on circadian rhythms in mammals have shown even minor deviations in the intensity and duration of environmental light at a given time of the day and it can alter or disrupt various chronobiologic rhythms. Piglets benefitted from increasing or long daylength $(15-18 \mathrm{hrs})$ increasing suckling leading to improved milk composition which culminated in heavier and larger litters at weaning, thus long or lengthening day-light (e.g. 16h or longer) increases food intake in growers/finishers (Claus and Weiler 1985; Taylor, 2010). The effect of a photoperiod signal is dependent on previously experienced photoperiod and a certain photoperiod can induce a long-day or a short-day response, depending on whether the previous photoperiod was shorter or longer (Stetson et al., 1989; Niklowitz et al., 1994). Therefore, effects of photoperiodism and pen colour on performance and production of grower pigs were investigated in this study.

\section{Materials and methods}

The study was carried out at the Piggery section, Teaching and Research Farm of the University of Ibadan, Ibadan, Oyo state, south western part of Nigeria. The location is $7^{2} 27 \mathrm{~N}$ and $3^{2} 45^{\prime} \mathrm{E}$ at altitude $200-300 \mathrm{~m}$ above sea level, the climate is humid tropical with mean temperature of $25-29^{2}$ ? and the average annual rainfall of about $1250 \mathrm{~mm}$. Forty-eight crossbred (Largewhite $x$ Landrace) grower pigs (gilts) at 16 weeks of age with average weight of $16.82 \pm 0.26 \mathrm{~kg}$ were randomly allotted to pens painted with different colours: pantone441 (control), pantone293 (blue), pantone185 (red) and pantone361 (green) and exposed to photoperiods of 12,15 and 18 hours. The experimental design was $4 \times 3$ factorial arrangement in a completely randomised design. Parameters measured were average feed intake $(\mathrm{kg})$, average weight gain $(\mathrm{kg})$ and feed conversion ratio and the data (feed intake, initial, final weight, weight changes and body weight gain), environmental, body and rectal temperature with the respiratory rate of each animals were taken weekly. The feed conversion ratio was calculated from the average feed intake and the weight gain. All 


\section{Adebiyi and Adelowo}

pigs were penned in a dwarf-walled, wellventilated, cement-floor building and the sides were raised with planks of $3 \mathrm{~m}$ to prevent the reflections of the coloured light rays into other pens. Electrification of the pens used for increased photoperiods was done with a compact fluorescent energy saver full spiral 18w of 46 lumens per watt bulb installed according to the colour of the pen. The pens were painted, disinfected and allowed to stand for four weeks before introducing the grower gilts. The grower gilts were acclimatised for two weeks and treated against internal and external parasitic infestation [they were dewormed with Lyvamesol, administered based on their body weight and Ivermetin $\left(1 \mathrm{~mL} \mathrm{~kg}^{-50}\right.$ body weight)]. During the 8 weeks of the study, the animals were fed twice (morning and evening) and water was provided in the various troughs ad libitum. The grower gilts were all fed similar diet to meet the NRC
(1998) requirements as shown in Table 1. Ambient temperature and relative humidity of the pens were measured with the aid of a thermo-hygrometer which was suspended in the pens. The temperature-humidity index (THI) was calculated as an indication of Heat stress index using the stated formula:

THI $\left({ }^{\circ} \mathrm{C}\right)=0.8 \mathrm{~T}+(\mathrm{RH} / 100) \times(\mathrm{T}-14.3)+$ 46.4

$\mathrm{THI} \geq 74$ is safe, $74<\mathrm{THI}<79$ is critical, $79 \leq \mathrm{THI}<84$ is dangerous and $\mathrm{THI} \geq 84$ is emergency [NOAA, 1976]

Statistical Analysis

Data obtained from the experiment were analysed using the statistical analysis of variance (ANOVA) procedure of SAS (2010) and significant level of $p=0.05$ was used. The treatment means were compared using the Tukey HSD option of the same software.

Table 1: Percentage composition of experimental diet.

\begin{tabular}{lr}
\hline Ingredient & Percentage (\%) \\
\hline Maize & 45.00 \\
Wheat offal & 36.75 \\
Groundnut cake & 10.00 \\
Full fat soya & 3.00 \\
Fish meal & 2.00 \\
Bone meal & 1.00 \\
Oyster shell & 1.00 \\
Lysine & 0.25 \\
Methionine & 0.25 \\
Vit./Min. Premix & 0.25 \\
Salt & 0.50 \\
Total & $\mathbf{1 0 0 . 0 0}$ \\
Calculated analysis & 17.68 \\
Crude Protein (\%) & 2627.43 \\
Metabolisable energy (kca/kg ME) & 0.94 \\
Calcium (\%) & 0.68 \\
Phosphorus (\%) & 0.91 \\
Lysine (\%) & 0.52 \\
Methionine (\%) & 4.74 \\
Crude Fibre (\%) & \\
\hline ME= Metabolisable energy, Vit./Min. = Vitamin/Mineral, b m= bean meal \\
*Composition of premix per kg of diet: vitamin A:(12,000,000 i.u); vitamin D3 (2,500,000 i.u); \\
vitamin E (30,000 mg); vitamin K3 (2,000 mg); vitamin B1( 2250 mg); vitamin B2( 6000 mg); \\
vitamin B6 (4,500 mg); vitamin B12 (15 meg); niacin (40,000 mg); pantothenic acid (15,000 mg); \\
folic acid (1,500 mg); biotin (50 meg); choline chloride (300,000 meg); manganese (80,000 mg); \\
zinc (50,000 mg); iron (20,000 mg); copper (5,000 mg); iodine ( 1,000 mg); selenium (200 mg); \\
cobalt (500 mg); antioxidant (125,000 mg)
\end{tabular}




\section{Photoperiodism and pen colouration}

\section{Results}

Results of the main effect of pen colour on performance characteristics of grower gilts are presented in Table 2. The final weight of grower gilts in the red pens increased significantly $(33.68 \pm 0.78 \mathrm{~kg})$ compared to those in control pens $(32.18 \pm 0.57 \mathrm{~kg})$, blue pens $(31.45 \pm 1.97 \mathrm{~kg})$ and green pens $(31.00 \pm 2.13 \mathrm{~kg})$. The results of the feed intake revealed that grower gilts in blue pens consumed more feed $(9.25 \pm 2.02 \mathrm{~kg})$, than those in control, red and green
$(7.91 \pm 0.30 \mathrm{~kg}, 8.46 \pm 0.73 \mathrm{~kg}$ and $7.87 \pm 0.22$ $\mathrm{kg}$ respectively) pens. The average weight gain increased significantly $(p<0.05)$ for gilts in red pens $(2.10 \pm 0.10 \mathrm{~kg})$ compared to those observed for control, blue and green $(1.92 \pm 0.10 \mathrm{~kg}, 1.83 \pm 0.54 \mathrm{~kg}$ and $1.77 \pm 0.25$ $\mathrm{kg}$ respectively) pens. FCR values also revealed significant $(\mathrm{p}<0.05)$ value for gilts in red $(4.02 \pm 0.30 \mathrm{~kg})$ compared to their counterparts in blue $(5.05 \pm 0.79 \mathrm{~kg})$, green $(4.54 \pm 0.75 \mathrm{~kg})$ and control $(4.13 \pm 0.22 \mathrm{~kg})$.

Table 2: Main effect of pen colour on performance characteristics of gilts at grower Stage

\begin{tabular}{llllll}
\hline Parameters & \multicolumn{2}{c}{ Colour } & \multicolumn{3}{c}{ SEM } \\
\cline { 2 - 5 } & Control & Blue & Red & Green & \\
\hline Initial weight/pig (kg) & 16.85 & 16.78 & 16.85 & 16.84 & 0.46 \\
Final weight/pig (kg) & $32.18^{\mathrm{b}}$ & $31.45^{\mathrm{b}}$ & $33.68^{\mathrm{a}}$ & $31.00^{\mathrm{b}}$ & 0.93 \\
Average weight gain (kg)/pig/week & $1.92^{\mathrm{b}}$ & $1.83^{\mathrm{b}}$ & $2.10^{\mathrm{a}}$ & $1.77^{\mathrm{b}}$ & 0.08 \\
Average feed intake (kg)/pig/week & $7.91^{\mathrm{c}}$ & $9.25^{\mathrm{a}}$ & $8.46^{\mathrm{b}}$ & $7.87^{\mathrm{c}}$ & 0.04 \\
Feed conversion ratio & $4.13^{\mathrm{bc}}$ & $5.05^{\mathrm{a}}$ & $4.02^{\mathrm{c}}$ & $4.54^{\mathrm{b}}$ & 0.13 \\
\hline
\end{tabular}

${ }^{\mathrm{abc}}$ Means along the same row with different superscripts are significantly different $(\mathrm{p}<0.05)$

From the results presented in Table 3, there were no significant $(p>0.05)$ differences in the final weight and the average weight gain per week of the gilts across the treatments. The feed intake $(9.21 \pm 1.68 \mathrm{~kg})$ of gilts under $12 \mathrm{~h}$ photoperiod was significantly $(p<0.05)$ greater than that of those under
$15 \mathrm{~h}$ and $18 \mathrm{~h}$ photoperiods $(7.81 \pm 0.19 \mathrm{~kg}$ and $7.97 \pm 0.19 \mathrm{~kg}$ respectively). There was also significant $(\mathrm{p}<0.05)$ variation in the feed conversion ratio and the gilts under $12 \mathrm{~h}$ photoperiod had the highest value of $4.84 \pm 0.83$. The FCR values of gilts under $15 \mathrm{~h}$ and $18 \mathrm{~h}$ photoperiods were $4.27 \pm 0.59$ and $4.22 \pm 0.52$ respectively.

Table 3: Main effect of increased photoperiod on performance of gilts at grower stage

\begin{tabular}{lllll}
\hline Parameters & \multicolumn{3}{c}{ Time } & SEM \\
\cline { 2 - 4 } & $12 \mathrm{~h}$ & $15 \mathrm{~h}$ & $18 \mathrm{~h}$ & \\
\hline Initial weight/pig $(\mathrm{kg})$ & 16.73 & 16.92 & 16.89 & 0.28 \\
Final weight/pig $(\mathrm{kg})$ & 32.11 & 31.79 & 32.20 & 0.56 \\
Average weight gain $(\mathrm{kg}) / \mathrm{pig} /$ week & 1.92 & 1.86 & 1.91 & 0.05 \\
Average feed intake(kg)/pig/week & $9.21^{\mathrm{a}}$ & $7.81^{\mathrm{b}}$ & $7.97^{\mathrm{b}}$ & 0.02 \\
Feed conversion ratio & $4.84^{\mathrm{a}}$ & $4.27^{\mathrm{b}}$ & $4.22^{\mathrm{b}}$ & 0.08 \\
\hline
\end{tabular}

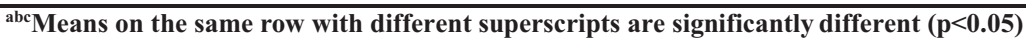

The effect of pen colour on rectal temperature of the gilts is shown in Figure1. The gilts in red pens had average rectal temperature of $39.45 \pm 0.34$ ?? , while their counterparts in control and blue pens had average rectal temperature of $39.43 \pm 0.50$ ? and $39.43 \pm 0.36$ ?? respectively. 


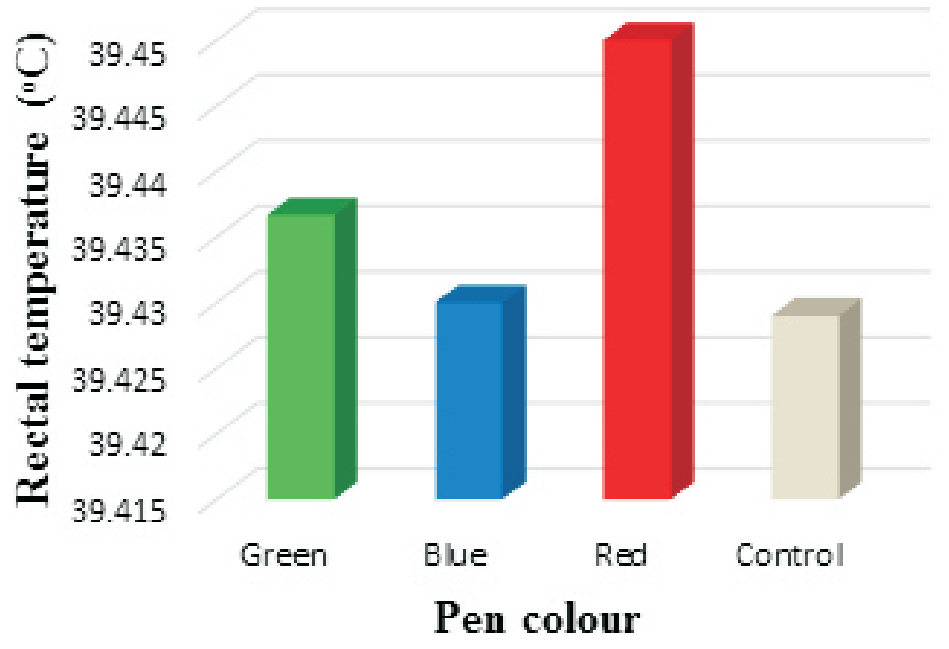

Figure 1: The effect of pen colour on rectal temperature of gilts at grower stage

Photoperiod also had no significant $(\mathrm{p}>0.05)$ effect on the rectal temperature of the gilts. Gilts under $18 \mathrm{~h}$ photoperiod had average rectal temperature of 39.41 ? , while gilts under $15 \mathrm{~h}$ photoperiod had average rectal temperature of 39.39 ?? .The gilts under $12 \mathrm{~h}$ photoperiod had average rectal temperature of 39.38 ?? (Figure 2).

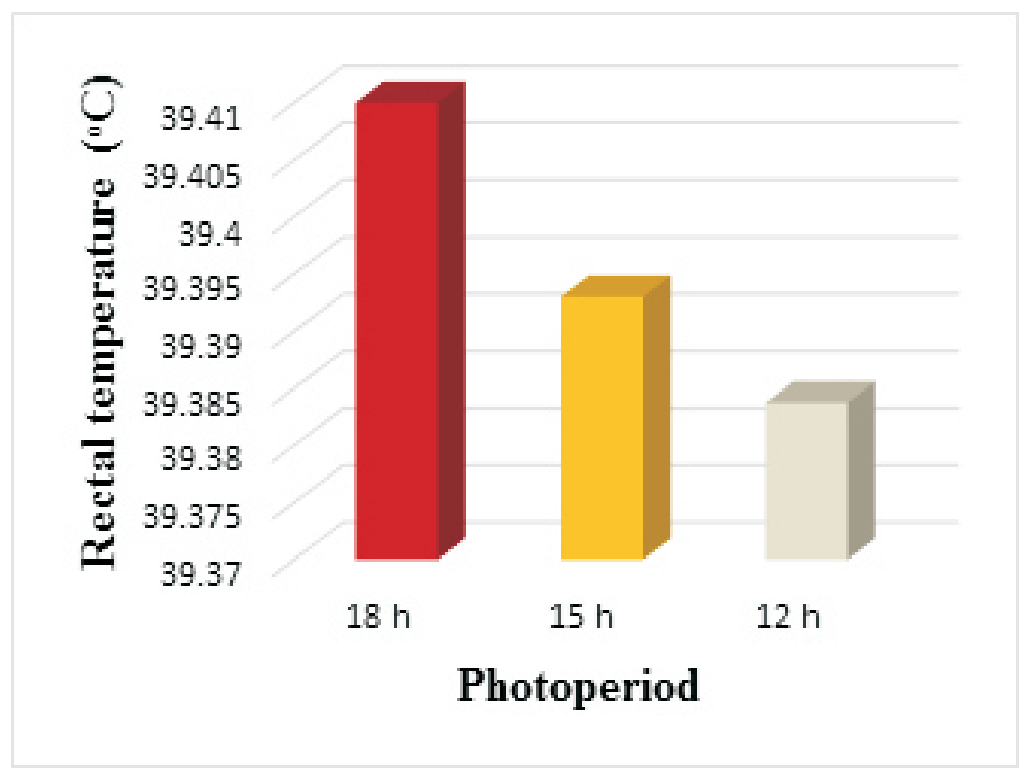

Figure 2: The effect of photoperiod on rectal temperature of gilts at grower stage 
Figure 3 shows the effect of pen colour on respiratory rate of gilts at grower stage. There were no significant variations in the values of the average respiratory rate across the treatments. The average respiratory rate for gilts in the red pens was $44.02 \pm 6.80$ breath/min, while the average respiratory rate for gilts in the control and green pens were $43.99 \pm 5.25$ breath $/ \mathrm{min}$ and $43.22 \pm 4.35$ breath $/ \mathrm{min}$ respectively. The gilts in the blue pen had the lowest average respiratory rate of $43.00 \pm 4.37$ breath $/ \mathrm{min}$.

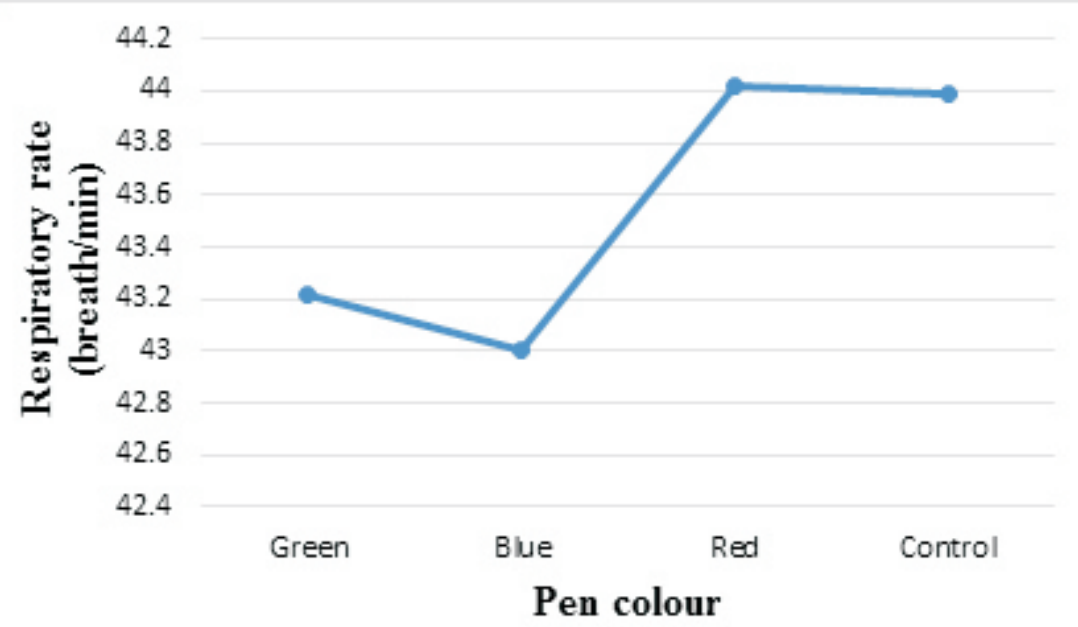

Figure 3: The effect of pen colour on respiratory rate of gilts at grower stage

It was observed that the THI reduced as the study progresses from 79.46 to 71.82 . The highest value observed at the inception of the study was 79.46 and it declined to 78.79 after two weeks of the study. At week four, a further decline was observed in the THI (76.82), week six (74.14) and finally 71.28 at the end of week eight. This result is shown in Figure 5.

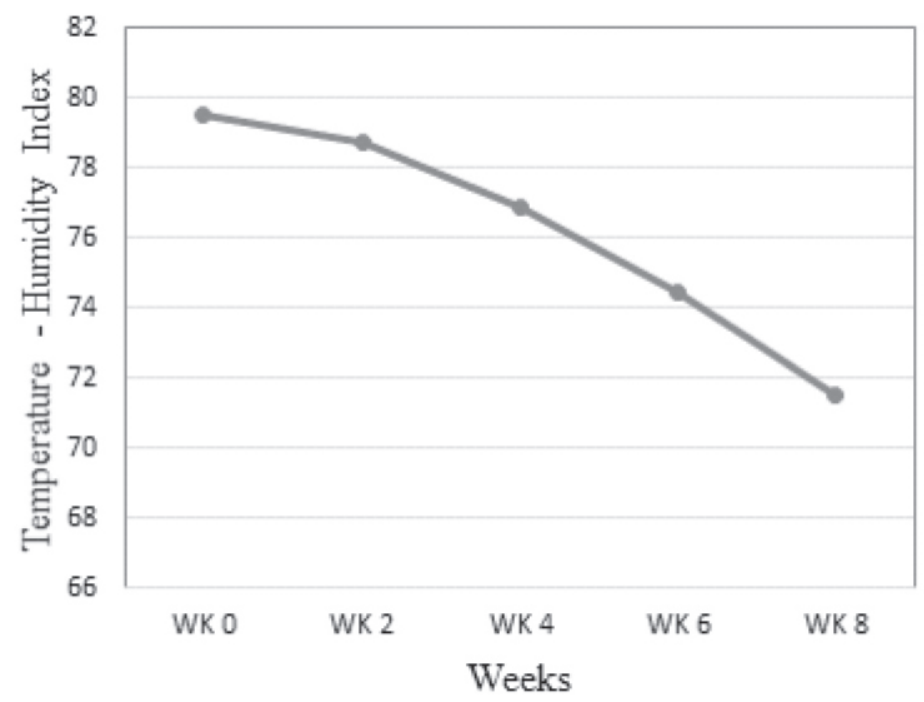

Figure 4: Ambient temperature and humidity curve for the period of experiment 


\section{Adebiyi and Adelowo}

Table 4: Interaction means of pen colour $\mathrm{x}$ photoperiod on performance of grower gilts

\begin{tabular}{llllll}
\hline Photoperiod & Colour & FWT(kg) & AWG $(\mathrm{kg})$ & FI $(\mathrm{kg})$ & FCR \\
\hline \multirow{3}{*}{$12 \mathrm{~h}$} & Control & $32.18 \pm 0.57^{\mathrm{a}}$ & $1.77 \pm 0.20^{\mathrm{a}}$ & $7.91 \pm 0.30^{\mathrm{c}}$ & $4.50 \pm 0.39$ \\
& Blue & $33.00 \pm 1.41^{\mathrm{a}}$ & $2.56 \pm 0.09^{\mathrm{a}}$ & $11.79 \pm 0.01^{\mathrm{a}}$ & $4.62 \pm 0.17$ \\
& Red & $34.25 \pm 0.50^{\mathrm{a}}$ & $2.03 \pm 0.07^{\mathrm{ab}}$ & $9.07 \pm 0.99^{\mathrm{b}}$ & $4.48 \pm 0.58$ \\
& Green & $29.00 \pm 0.82^{\mathrm{b}}$ & $1.91 \pm 0.12^{\mathrm{b}}$ & $8.07 \pm 0.26^{\text {bc }}$ & $4.25 \pm 0.33$ \\
& & & & & \\
& & & & \\
& Control & $31.08 \pm 0.46^{\mathrm{ab}}$ & $1.66 \pm 0.30^{\mathrm{c}}$ & $7.20 \pm 0.0 .41^{\mathrm{d}}$ & $4.30 \pm 0.20$ \\
$\mathrm{~h}$ & Blue & $29.50 \pm 1.29^{\mathrm{b}}$ & $2.16 \pm 0.14^{\mathrm{a}}$ & $7.68 \pm 0.10^{\text {cd }}$ & $3.57 \pm 0.25$ \\
& Red & $33.13 \pm 0.25^{\mathrm{a}}$ & $2.11 \pm 0.14^{\mathrm{a}}$ & $8.06 \pm 0.10^{\mathrm{bc}}$ & $3.85 \pm 0.40$ \\
& Green & $32.75 \pm 0.96^{\mathrm{a}}$ & $2.33 \pm 0.12^{\mathrm{a}}$ & $7.71 \pm 0.14^{\mathrm{c}}$ & $3.32 \pm 0.15$ \\
& & & & & \\
& Control & $31.00 \pm 0.58^{\mathrm{ab}}$ & $1.60 \pm 0.10^{\mathrm{c}}$ & $7.00 \pm 0.50^{\mathrm{d}}$ & $4.55 \pm 0.10$ \\
& Blue & $32.00 \pm 1.00^{\mathrm{a}}$ & $1.98 \pm 0.09^{\mathrm{b}}$ & $7.94 \pm 0.22^{\mathrm{c}}$ & $4.10 \pm 0.24$ \\
& Red & $33.67 \pm 1.15^{\mathrm{a}}$ & $2.00 \pm 0.12^{\mathrm{ab}}$ & $8.19 \pm 0.10^{\mathrm{bc}}$ & $4.01 \pm 0.31$ \\
& Green & $31.25 \pm 2.36^{\mathrm{ab}}$ & $1.89 \pm 0.19^{\mathrm{b}}$ & $7.83 \pm 0.01^{\mathrm{c}}$ & $4.18 \pm 0.45$ \\
& P value & $<.0001$ & $<.0001$ & $<.0001$ & 0.3728 \\
\hline
\end{tabular}

FWT $=$ final weight, $\mathrm{AWG}=$ average weight gain, $\mathrm{FI}=$ feed intake, $\mathrm{FCR}=$ feed conversion ratio, $\mathrm{h}=$ hour, $\mathrm{Pc}=\mathrm{Pen} \operatorname{colour}, \mathrm{P}=$ photoperiod, ${ }^{\text {abc } M e a n s ~ o n ~ t h e ~ s a m e ~ c o l u m n ~ w i t h ~ d i f f e r e n t ~ s u p e r s c r i p t s ~ a r e ~ s i g n i f i c a n t l y ~ d i f f e r e n t ~ a t ~}(p<0.05)$

\section{Discussion}

The higher final weight observed for gilts in red pen suggested that this colour resulted in increased activity of the animal which helped in better feed utilisation thus building up of body mass and this corroborated the findings of Wheelhouse and Hacker (1982) and Peichl and Moutairou (1997) in their studies with growers. The authors reported that 65lux red light gave heavier body weight and increased daily gain compared with 65lux uv, 500 lux cool white and 650 lux daylight. These results confirmed earlier report by Taylor (2010), which revealed that the grower pigs have photoreceptor and ganglion cell density within the eye which suggested a theoretical potential for good acuity compared with other mammals. It was also observed that the average weight gain of growers at this stage varied significantly $(p<0.05)$ across the treatments and the gilts in red had the highest value compared to those in control, blue and green pens. The feed conversion ratio values were also significantly $(\mathrm{p}<0.05)$ different across the treatments. Adelowo and Adebiyi (2016) reported that red colour attracted gilts thus becoming active and consumed more feed.

Photoperiod is a factor in pig production that cannot be underestimated, as it has significant effect in productivity, wellbeing and overall performance of pigs (Rivera et al., 2005). In the present study, performance (growth) of the gilts was found to be increasing as photoperiod increased. The result was in agreement with the report of Taylor (2010) which showed that long or lengthen day lengths (e.g. 16h or longer) increase feed intake in growers/finishers. The findings is in variance with the results of Dureau et al., (1996) and Adelowo and Adebiyi (2016), who reported that animals experiencing four or more weeks of continuous illuminance lost up to $20 \%$ body weight, indicating either behavioural disinclination to eat, possibly due to discomfort, or to stress associated with the extreme lighting conditions. The differences in the reports could be due to the stage of growth of the pigs. Pigs in this study were in their active growth period while continuous 


\section{Photoperiodism and pen colouration}

feeding and extended illumination resulted in better performance at 15 and $18 \mathrm{~h}$ over $12 \mathrm{~h}$ as revealed in the feed conversion ratio. The interactions of pen colour and increased photoperiods also revealed that grower pigs in red pens at $18 \mathrm{~h}$ had better feed conversion ratio. This revealed the positive interrelationship between colour and photoperiods as it affects animal performance.

The gilts in the red pen were observed to have the highest rectal temperature and respiratory rates because the gilts were more active when compared to those in other treatments hence experienced increased body metabolism. Also, the rectal temperature and respiratory rate were discovered to increase as the photoperiod increased which might have resulted in the discomfort and stress experienced by the gilts at this period. The temperature humidity index was high at inception but reduced as the study progressed which resulted in stability and improved performance of the gilts and this supports the report of Rivera et al. (2005) that temperature and light are major environmental factors affecting animal physiology with temperature being considered the most important factor.

\section{Conclusion}

At the grower stage, gilts housed in red pens had increased average weight gain, reduction in feed conversion ratio and general improved performance. Increasing the photoperiod resulted in better feed utilisation of the gilts at grower stage.

\section{Ethical declaration}

All authors hereby declare that "Principles of laboratory animal care" (NIH publication No. 85-23, revised 1985) were followed, as well as specific national laws where applicable.

\section{Acknowledgement}

The authors will like to acknowledge the Tertiary Education Trust Fund (TETFUND), Nigeria for sponsoring this research work.

\section{Competing interests}

Authors have declared that no competing interests exist.

\section{References}

Adelowo, O. V. and Adebiyi, O. A. 2016. The Effect of Pen Colour and Increased Photoperiod o n Performance of Weaned Gilts. British Biotechnology Journal 16(2): 1-7.

Claus, R. and Weiler, U. 1985. Influence of light and photoperiodicity on pig prolificacy, J. Reprod. Fertil. Suppl. 33; 185-197.

Dureau, P., Jeanny, J. C., Clerc, B., Dufier, J. L. and Courtois, Y. 1996. Long term light - induced retinal degeneration in the miniature pig. Molecular Vision 2(7):Pp.198-204

Hemsworth, H. 2007. Hemsworth H. Behavioural Principles of Pig Handling. In: Grandin, T. (Ed.). Livestock Handling and Transport, 3rd edn. Preston, UK: A M A Dataset, 2007; Pp. 214-227.

NOAA 1976. National Oceanic and Atmospheric Administration. Livestock Hot Weather S t r e s s . Operations Manual Letter c-31-76. Kansas City

Neitz, J. and Jacobs, G. H., 1989. Spectral sensitivity of cones in an ungulate. Visual Neuroscience. 2: pp.97 100.

Niklowitz, P., Lerchl, A. and Nieschlag, E. 1994. Photoperiodic responses in 
Djungarian hamsters (Phodopus sungorus): Importance of light history for pineal and serum melatonin profiles. Biol Reprod. 5 $1: 714-724$.

NRC (1998). Nutrient Requirement of Swine (10 ${ }^{\text {th }}$ Revised Ed.). Sub Committee on Animal Nutrition, National Research Council 210pp

Peichl, L., and Moutairou, K. (1997). Absence of blue cones in the retinae of some mammals. Investigating Ophthalogical Vision Science 38 (4) p331-331.

Tanida, H., Miura, L., Tanaka, T. and Yoshimoto, T. 1996. Behavioural responses of $\mathrm{p} \mathrm{ig} \mathrm{le} \mathrm{t} \mathrm{s} \mathrm{t} \mathrm{o}$ darkness and shadows. Applied Animal Behaviour Science 49:173 -183 .

Rivera, M. M., Quintero-Moreno, A., Barrera, X., Palomo, M. J., Rigau, T. and Rodríguez-Gil, J. E. 2005. Natural mediterranean photoperiod does not affect the main parameters of $\quad \mathrm{b}$ o $\mathrm{a} \mathrm{r}$ semen quality analysis. Theriogenology.64:934-946.
SAS 2010. SAS/STAT User's Guide: Version 9.2. SAS Institute Inc., Cary. NC., USA, 2010.

Stetson, M. H, Ray S. L, Creyaufmiller, N. and Horton, T. H. 1989. Maternal transfer of Photoperiodic information in Siberian hamsters. 11. The nature of the maternal signal, time of signal transfer, and the effect of the maternal signal on peripubertal reproductive development in the absence of photoperiodic input. Biol Reprod. 40:458-465.

Taylor, N. R. 2010. Lighting for pig units. Report compiled for BPEX.

Taylor, N. R. 2006. Lighting and the welfare of pigs. Unpublished Ph.D. Thesis. University of Bristol. Pp. 20-30

Wheelhouse, R. K. and Hacker, R. R. 1982. Effect of different types of light on grow th and reproductive performance in gilts. Canadian Journal of Animal Science. 61(4):1081.

Received: $18^{\text {th }}$ March, 2017

Accepted: 25 ${ }^{\text {th }}$ June, 2017 